06

\title{
Электрические свойства пленочных нанокомпозитов на основе аморфного гидрогенизированного углерода
}

\author{
(С) Г.А. Николайчук, О.Ю. Мороз, С.М. Дунаевский \\ Акционерное общество «Научно-исследовательский институт «Феррит-Домен», \\ 196084 Санкт-Петербург, Россия \\ ฯ e-mail: o.y.moroz@domen.ru
}

(Поступило в Редакцию 28 декабря 2017 г.)

\begin{abstract}
Представлены результаты исследований электрических свойств пленок аморфного гидрогенизированного углерода с наночастицами никеля $a-\mathrm{C}: \mathrm{H}(\mathrm{Ni})$ на подложках из ситалла. Синтез пленок проведен методом реактивного ионно-плазменного магнетронного напыления. Приведены результаты исследований влияния концентрации никеля $(\mathrm{Ni})$ на величину проводимости $(\sigma)$ при постоянном токе и значения комплексной диэлектрической проницаемости $\left(\varepsilon^{*}\right)$ в диапазоне частот $8-12 \mathrm{GHz}$. Значение действительной части комплексной диэлектрической проницаемости $\left(\varepsilon^{\prime}\right)$ образцов достигало 100 , мнимой части $\left(\varepsilon^{\prime \prime}\right)-212$. Концентрация никеля в пленках, соответствующая порогу протекания, составляла $22-25$ at.\%.
\end{abstract}

DOI: 10.21883/JTF.2018.11.46628.2627

\section{Введение}

Пленки аморфного гидрогенизированного углерода $a-\mathrm{C}: \mathrm{H}$ представляют научный и практический интерес в связи с уникальными механическими и оптическими свойствами. Результаты исследований свойств и структуры пленок $a$-С:Н приведены в работах отечественных и зарубежных авторов [1-9]. Структура пленок $a$-С:H описывается в рамках кластерной модели, согласно которой пленки представляют собой смесь наноразмерных графитоподобных и алмазоподобных кластеров, содержащих углерод в $s p^{2}$ - и $s p^{3}$-состояниях соответственно [6,7]. Аморфный гидрогенизированный углерод является полупроводником, ширина запрещенной зоны которого зависит от концентрации водорода, и может быть прозрачным в ИК, видимой или ультрафиолетовой (УФ) спектральных областях [8,9].

Модификация пленок $a$-С:H атомами различных химических элементов позволяет изменять их свойства. Введение атомов фтора (F), кремния (Si) [10], азота $(\mathrm{N})$ [11], меди $(\mathrm{Cu})$, титана (Ti) [12], тантала (Тa), вольфрама (W) [13] значительно снижает коэффициент трения и повышает износостойкость пленок. Примеси бора (B), фтора (F) [14], кремния (Si) [15] повышают твердость. Вольфрам (W), хром (Cr) [16] позволяют изменять оптические свойства. Проводимость пленок может управляться с помощью введения атомов тантала $(\mathrm{Ta})$, вольфрама $(\mathrm{W})$, титана $(\mathrm{Ti})$, ниобия $(\mathrm{Nb})$ [17], серебра $(\mathrm{Ag})$, меди $(\mathrm{Cu})[18]$.

В приведенных работах получение пленок $a$-C:H, модифицированных различными химическими элементами, проводилось химическими методами (PECVD, MOCVD). Метод ионно-плазменного магнетронного напыления является более перспективным для получения нанокомпозитных пленок заданного состава с малыми радиационными дефектами, незначительным загрязнением посторонними газовыми включениями и хорошей адгезией пленки к подложке.
В работах $[19,20]$ исследовались температурные зависимости проводимости пленок $a-\mathrm{C}: \mathrm{H}(\mathrm{Co})$ и $a-\mathrm{C}: \mathrm{H}(\mathrm{Cu})$.

Диэлектрические свойства систем $a$-C:H(Ni) ранее изучались нами резонансным методом и приведены в $[21,22]$. В настоящей работе представлены результаты экспериментальных исследований пленок $a$-C:H(Ni) в диапазоне частот $8-12 \mathrm{GHz}$ методом волноводной линии передачи. Приведены частотные зависимости комплексной диэлектрической проницаемости и зависимости проводимости пленок от химического состава и микроструктуры.

\section{Описание образцов нанокомпозитных пленок}

Синтез тонких пленок состава $a$-C:H(Ni) проводился методом реактивного ионно-плазменного магнетронного распыления [23] графитовой и никелевой мишеней в атмосфере аргоно-водородной газовой смеси. Получены образцы пленок $a$-C:H(Ni) различного химического состава толщиной от $300 \mathrm{~nm}$ до $8 \mu \mathrm{m}$ на подложках из ситалла марки СТ-50-1.

Толщина пленок измерена с помощью компьютерного комплекса на основе интерферометра МИИ-4 и сканирующего электронного микроскопа MIRA LMU фирмы Tescan.

Исследования химического состава пленок проводились с помощью сканирующего электронного микроскопа VEGA II LMU с энергодисперсионным микроанализатором INCA Energy 350 DC. Погрешность измерений составляет $\pm 1.0 \%$.

На рис. 1 представлен энергетический спектр пленки $a$-C:H(Ni) на подложке из ситалла, полученный при ускоряющем напряжении $10 \mathrm{kV}$. В энергетическом спектре наблюдается основной пик, отвечающий $\mathrm{Ni}$, a также присутствуют пики, соответствующие элементам 


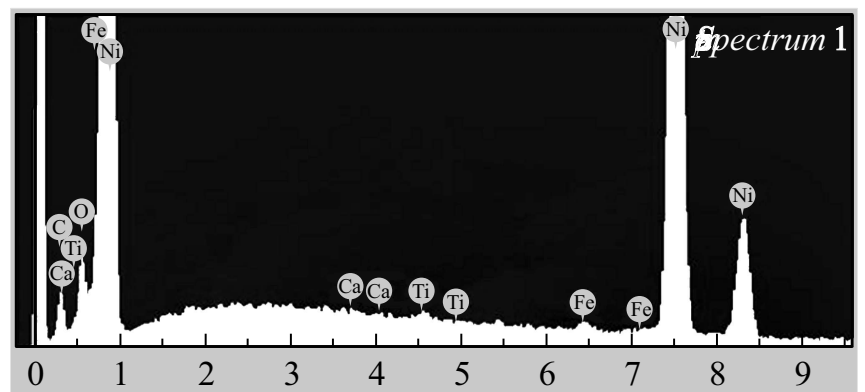

Ful Scale 1807 cts Cursor. -0.013 (4934 cts) $\mathrm{keV}$

Рис. 1. Энергетический спектр пленки $a-\mathrm{C}: \mathrm{H}(\mathrm{Ni})$, полученный с помощью энергодисперсионного спектрометра при ускоряющем напряжении $10 \mathrm{kV}$.

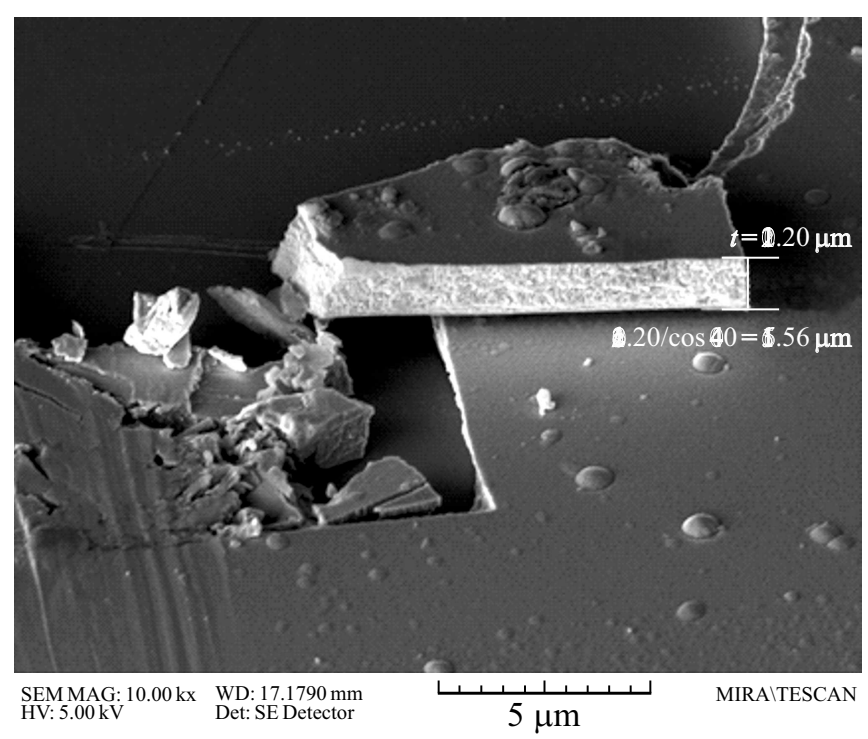

Рис. 2. Изображение пленки $a-\mathrm{C}: \mathrm{H}(\mathrm{Ni})$ на подложке из ситалла во вторичных электронах на микроскопе MIRA LMU.

подложки (Fe, $\mathrm{Ti}, \mathrm{Ca})$, что вызвано относительно малой толщиной пленки $a-\mathrm{C}: \mathrm{H}(\mathrm{Ni})$.

Содержание $\mathrm{Ni}$ находилось в пределах от 12.4 до 69.3 at.\%, содержание C - от 30.7 до 87.6 at.\%.

Морфология поверхности пленок исследовалась с помощью сканирующего электронного микроскопа MIRA LMU. На рис. 2 приведено изображение во вторичных электронах поверхности пленки $a-\mathrm{C}: \mathrm{H}(\mathrm{Ni})$ с каплеобразными включениями размерами от $100 \mathrm{~nm}$ до $2 \mu \mathrm{m}$.

\section{Исследование проводимости пленок $a-\mathrm{C}: \mathrm{H}(\mathrm{Ni})$}

Одной из основных характеристик композитных систем является порог протекания - значение концентрации атомов металла, при котором образуется бесконечный проводящий кластер [24].
Для исследования порога протекания в пленках $a-\mathrm{C}: \mathrm{H}(\mathrm{Ni})$ была изготовлена серия образцов толщиной $\sim 1 \mu \mathrm{m} \mathrm{с} \mathrm{содержанием} \mathrm{никеля} \mathrm{от} 12.4$ до 69.3 at.\%. Химический состав исследованных пленок приведен в табл. 1. Величина проводимости на постоянном токе рассчитывалась из результатов измерения удельного сопротивления.

Расчет удельного сопротивления пленок проводился на основании измеренных значений поверхностного сопротивления $R_{s}$ пленок по формуле

$$
\rho=R_{s} \cdot h,
$$

где $R_{s}$ - удельное поверхностное сопротивление пленок, $\Omega / \square, h$ - толщина пленки, $\mathrm{m}$.

Измерение поверхностного сопротивления проводилось четырехзондовым методом по методике, изложенной в [25], с помощью установки Jandel RMS-EL. Метод основан на явлении растекания тока в точке контакта металлического острия зонда с поверхностью пленки. Ток возбуждается через два внешних зонда, а разность электрических потенциалов измеряется между двумя внутренними зондами с помощью вольтметра с высоким входным сопротивлением.

На рис. 3 приведена зависимость удельного сопротивления образцов пленок $a-\mathrm{C}: \mathrm{H}(\mathrm{Ni})$ от содержания $\mathrm{Ni}$. Концентрация $\mathrm{Ni}$, соответствующая порогу протекания, составляет 22-25 at.\%.

Значения удельной проводимости образцов пленок с содержанием никеля выше порога протекания составляют от $0.9 \cdot 10^{5}$ до $1.8 \cdot 10^{6} \mathrm{~S} / \mathrm{m}$ и определялись на отдельной серии образцов. Химический состав и удельная проводимость образцов приведены в табл. 2. Увеличение содержания $\mathrm{Ni}$ в пленках на $10 \%$ соответствует росту проводимости в $2-2.5$ раза.

Таблица 1. Химический состав образцов пленок $a$-C:H(Ni)

\begin{tabular}{c|c|c}
\hline № образца & Содержание $\mathrm{Ni}$, at.\% & Содержание C, at.\% \\
\hline 1 & 12.4 & 87.6 \\
2 & 16.3 & 83.7 \\
3 & 21.0 & 79.0 \\
4 & 24.2 & 75.8 \\
5 & 37.2 & 62.8 \\
6 & 55.0 & 45.0 \\
7 & 69.3 & 30.7
\end{tabular}

Таблица 2. Удельная проводимость образцов пленок $a-\mathrm{C}: \mathrm{H}(\mathrm{Ni})$

\begin{tabular}{c|c|c}
\hline $\begin{array}{c}\text { № } \\
\text { образца }\end{array}$ & $\begin{array}{c}\text { Содержание } \\
\text { Ni, at.\% }\end{array}$ & $\begin{array}{c}\text { Удельная } \\
\text { проводимость } \sigma, \mathrm{S} / \mathrm{m}\end{array}$ \\
\hline 1 & 30.2 & $0.9 \cdot 10^{5}$ \\
2 & 42.0 & $2.0 \cdot 10^{5}$ \\
3 & 55.1 & $5.6 \cdot 10^{5}$ \\
4 & 65.3 & $1.1 \cdot 10^{6}$ \\
5 & 69.5 & $1.8 \cdot 10^{6}$
\end{tabular}


На рис. 4,5 приведены изображения поверхности пленок с концентрацией никеля до порога протекания (16 at.\%) и после порога протекания (55 at.\%), полученные с помощью сканирующего электронного микроскопа с использованием детектора отраженных электронов. Пленка с содержанием $\mathrm{Ni} 16$ at.\% имеет гранулированную структуру с ярко выраженными кластерными образованиями размерами до $3 \mu \mathrm{m}$. При концентрации никеля выше порога протекания в пленках наблюдается образование протяженных проводящих кластеров. Об-

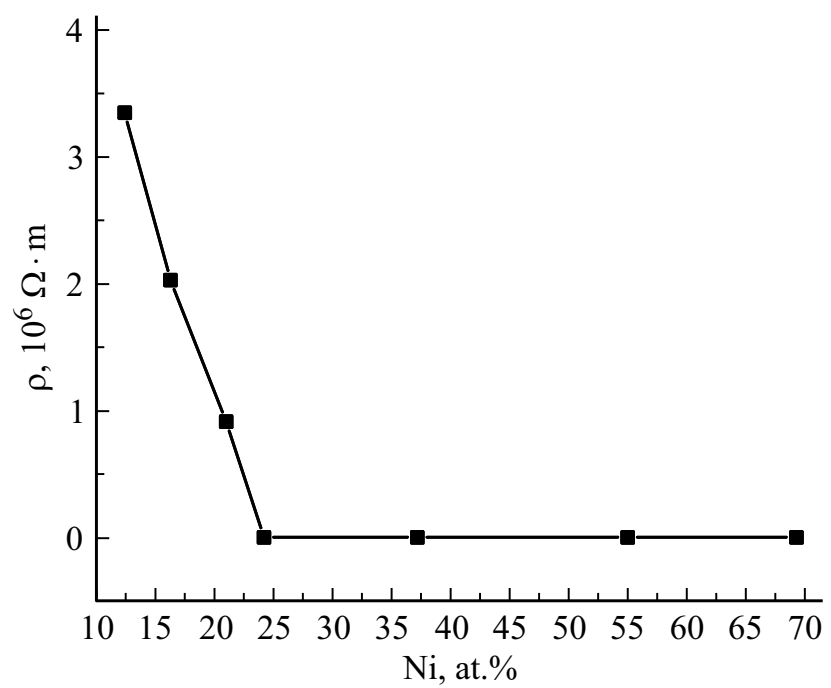

Рис. 3. Зависимость удельного сопротивления образцов пленок $a-\mathrm{C}: \mathrm{H}(\mathrm{Ni})$ от содержания $\mathrm{Ni}$.

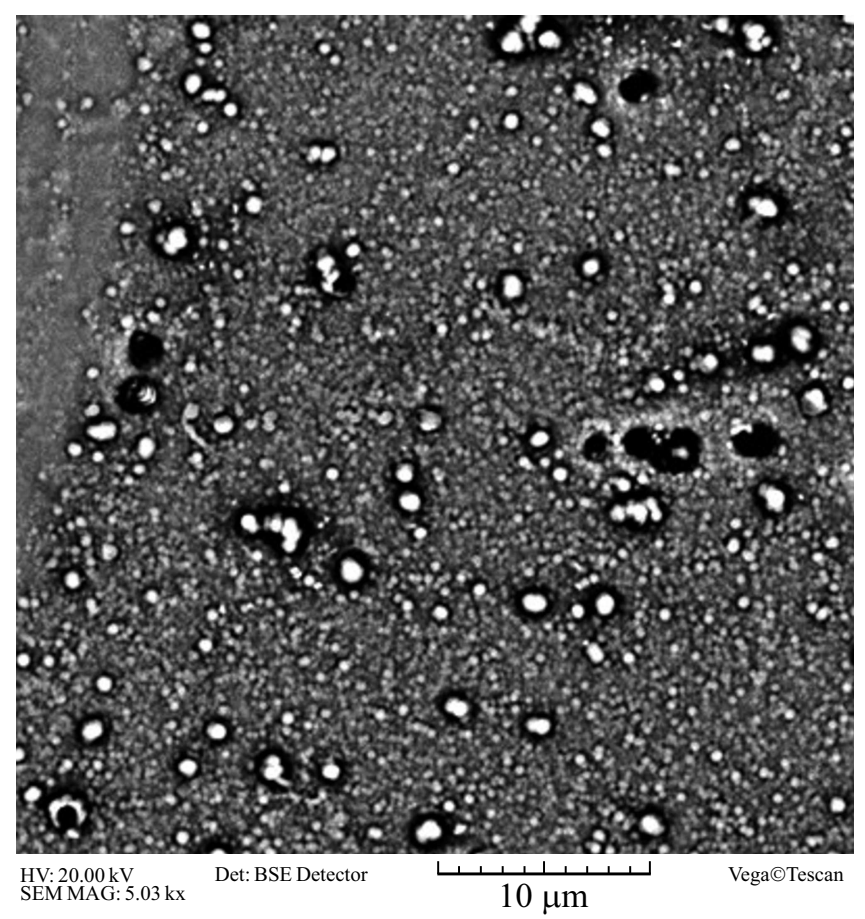

Рис. 4. Изображение пленки $a-\mathrm{C}: \mathrm{H}(\mathrm{Ni})$ с содержанием Ni 16 at.\% в отраженных электронах.

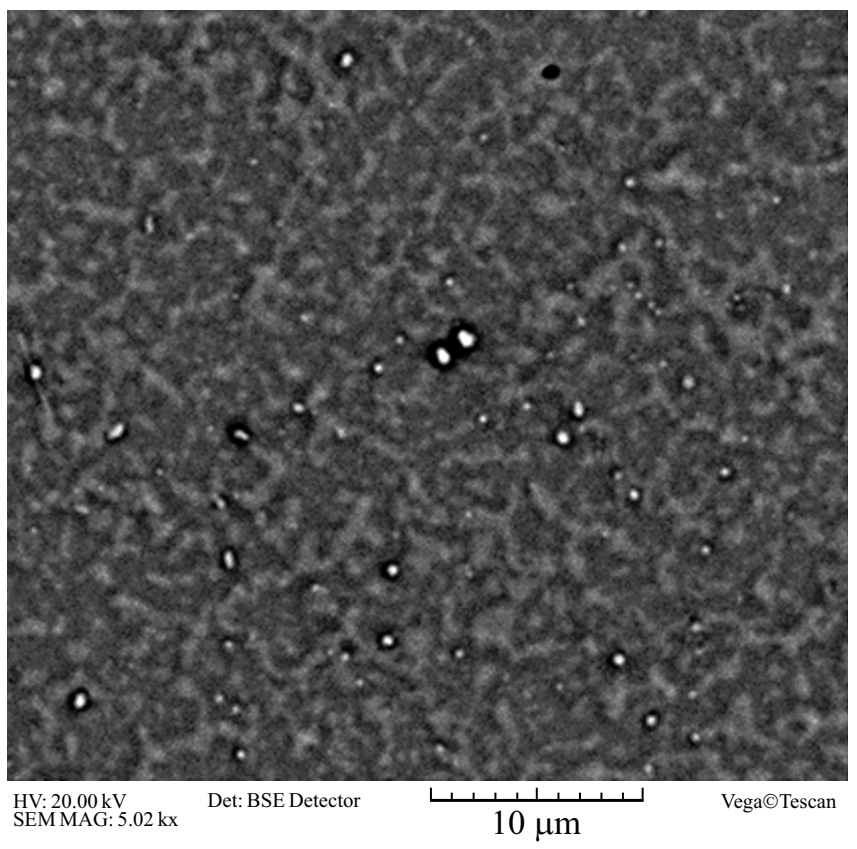

Рис. 5. Изображение пленки $a-\mathrm{C}: \mathrm{H}(\mathrm{Ni})$ с содержанием Ni 55 at.\% в отраженных электронах.

разцы с концентрацией никеля выше порога протекания имели металлический тип проводимости, что подтверждается линейным ходом зависимости сопротивления $R(T)$ в интервале температур от 200 до $300 \mathrm{~K}$.

\section{Исследование комплексной диэлектрической проницаемости пленок $a-\mathrm{C}: \mathrm{H}(\mathrm{Ni})$ в СВЧ диапазоне}

Исследования частотных зависимостей значений комплексной диэлектрической проницаемости $\left(\varepsilon^{*}\right)$ пленок состава $a-\mathrm{C}: \mathrm{H}(\mathrm{Ni})$ проводились методом линии передачи, изложенным в [26], с помощью ячейки на основе отрезка прямоугольного волновода с использованием векторного анализатора цепей Agilent PNA 5227 в диапазоне частот 8-12 GHz. Схема установки приведена на рис. 6.

Значения $\varepsilon^{*}$ рассчитаны по результатам измерений отраженного $\left(S_{11}\right)$ и прошедшего $\left(S_{22}\right)$ сквозь ячейку с образцом сигналов по моделям Nicholson-Ross- Weir [27,28] и Polynomial Fit [29]. В модели Nicholson-Ross-Weir расчет значений $\varepsilon^{*}$ проводится на основе экспериментальных значений коэффициентов отражения $\left(S_{11}\right)$ и передачи $\left(S_{12}\right)$ ячейки с образцом, при этом критерием остановки алгоритма расчета является равенство расчетных и экспериментальных значений группового времени запаздывания сигнала в ячейке. В модели Polynomial Fit производится расчет коэффициентов $S_{11}$ и $S_{12}$ по значениям $\varepsilon^{*}$, полученным в результате полиномиального приближения. Критерием остановки алгоритма расчета 


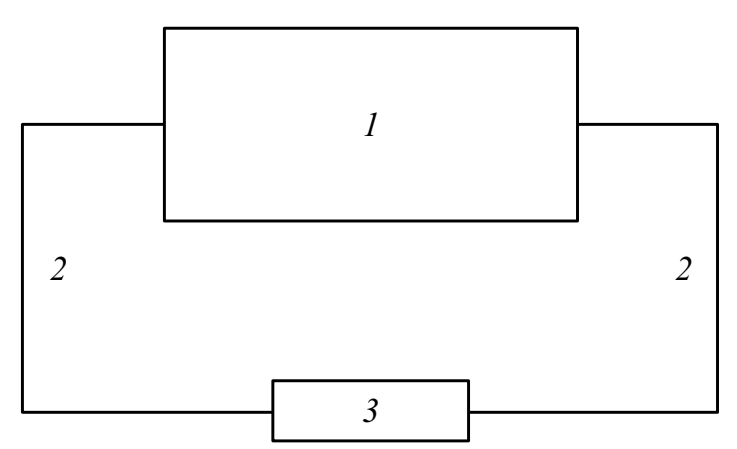

Рис. 6. Схема установки для измерения комплексной диэлектрической проницаемости пленок $a$-C:H(Ni), где 1 - векторный анализатор цепей, $2-\mathrm{CBЧ} \mathrm{кабели,} 3$ - измерительная ячейка с образцом.

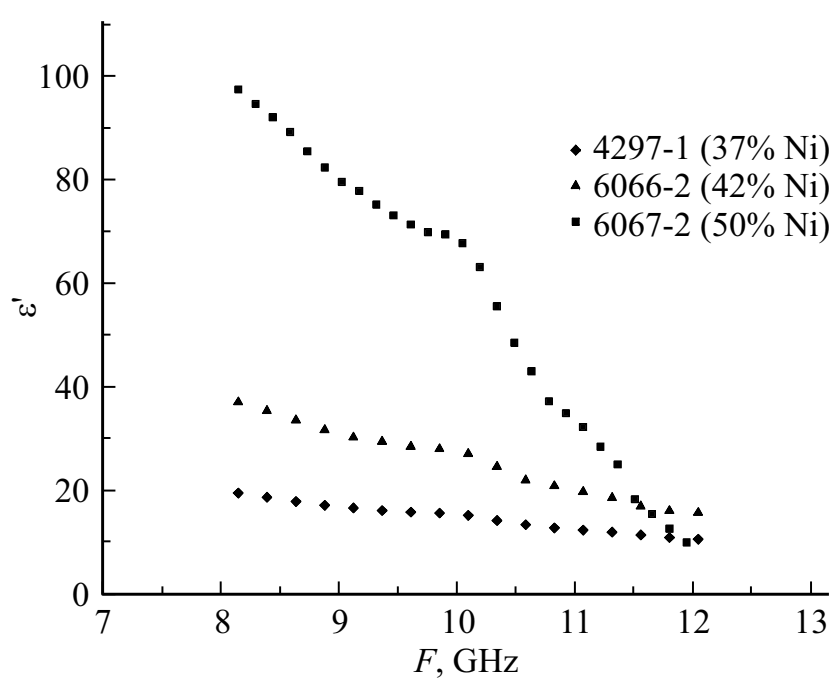

Pис. 7. Частотные зависимости действительной части диэлектрической проницаемости пленок $a-\mathrm{C}: \mathrm{H}(\mathrm{Ni})$ на подложках из ситалла.

является равенство расчетных и экспериментальных значений $S_{11}$ и $S_{12}$.

В качестве эталонного образца использовалась подложка из ситалла марки СТ-50-1. По результатам исследований действительная часть диэлектрической проницаемости подложки на частоте $10 \mathrm{GHz}$ составляет 8.8 , тангенс диэлектрических потерь $-4.2 \cdot 10^{-3}$, что соответствует литературным данным [30]. Пленка аморфного гидрогенизированного углерода $a-\mathrm{C}: \mathrm{H}$ на подложке из ситалла имеет такие же значения диэлектрической проницаемости в рассматриваемом диапазоне частот.

Частотные зависимости действительной и мнимой частей комплексной диэлектрической проницаемости образцов пленок $a-\mathrm{C}: \mathrm{H}(\mathrm{Ni})$ в диапазоне частот $8-12 \mathrm{GHz}$ приведены на рис. 7 и 8. Значения $\varepsilon^{\prime}$ составляют от 10 до $100, \varepsilon^{\prime \prime}$ - от 30 до 212. Результаты вычислений по моделям Nicholson-Ross-Weir и Polynomial Fit совпадали с точностью до $5 \%$.

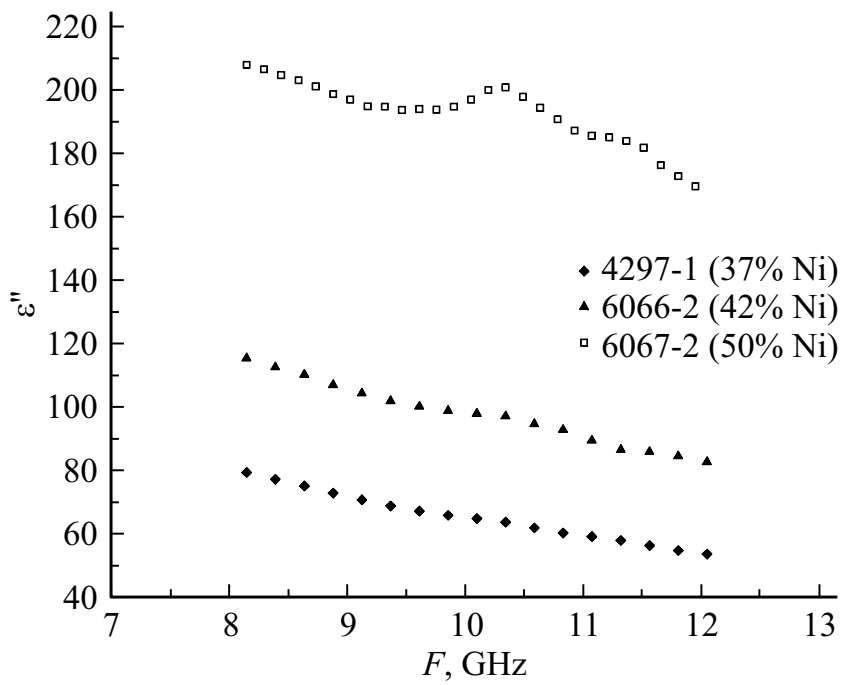

Рис. 8. Частотные зависимости мнимой части диэлектрической проницаемости пленок $a-\mathrm{C}: \mathrm{H}(\mathrm{Ni})$ на подложках из ситалла.

Полученные результаты показывают, что с увеличением содержания никеля в пленке аморфного гидрогенизированного углерода значения действительной и мнимой частей диэлектрической проницаемости резко возрастают. Ход частотных зависимостей достаточно монотонный, что позволяет предположить, что в рассматриваемом диапазоне частот в пленках преобладают диэлектрические механизмы, не связанные с дипольной релаксацией. Такой вид зависимостей наблюдается у материалов, в которых характер диэлектрического отклика определяется свободными носителями заряда [31].

Известно, что введение в состав аморфных полупроводников атомов металла может привести к появлению электронно-активных центров и вызвать примесную проводимость, как это происходит в кристаллических полупроводниках. В нашем случае модификация пленки $a$-С:Н наночастицами $\mathrm{Ni}$, вероятно, привела к внедрению атомов Ni в нанокластеры углерода без формирования связи $\mathrm{Ni}-\mathrm{C}$ (т.е. по механизму интеркаляции), как это имеет место в работах Иванова-Омского при исследовании $a-\mathrm{C}: \mathrm{H}(\mathrm{Cu})[32]$.

Увеличение диэлектрической проницаемости нанокомпозита $a$-C:H(Ni) по сравнению с диэлектрической проницаемостью матрицы $a-\mathrm{C}: \mathrm{H}$ определяется поляризацией проводящих частиц при приложении электрического поля. Квазистатический предел в пленках, при котором все проводящие частицы поляризуются, определяется выражением [33]

$$
v \ll \sigma /\left(2 \pi \varepsilon_{0} \varepsilon_{m}\right)=v_{g},
$$

где $\sigma$ - проводимость пленки, $\varepsilon_{m}-$ диэлектрическая проницаемость матрицы, $\varepsilon_{0}=8.85 \cdot 10^{-12} \mathrm{~F} / \mathrm{m}$. Квазистатический предел в пленках составляет $v \ll 10^{15} \mathrm{~Hz}$, что выполняется для рассматриваемого частотного диапазо- 
на и позволяет предположить, что металлические наночастицы в пленке полностью поляризуются под воздействием электрического поля и при отсутствии перколяции диэлектрическая проницаемость не должна зависеть от частоты. В нашем случае значения действительной и мнимой частей диэлектрической проницаемости снижались с ростом частоты. Характер полученных частотных зависимостей диэлектрической проницаемости позволяет предположить, что диэлектрические свойства пленок обусловлены не только поляризацией частиц, но и другими механизмами.

Такими механизмами могут являться:

1. Процессы межфазной поляризации, обусловленные переносом заряда через контактные сопротивления между кластерами [34], а также изменениями электронной структуры межфазного пространства у границы кластера за счет графитизации аморфного углерода при контакте с металлом [35].

2. Случайные взаимодействия свободных носителей заряда при движении по проводящим каналам [36].

\section{Заключение}

Проведены исследования комплексной диэлектрической проницаемости в диапазоне частот $8-12 \mathrm{GHz}$ и проводимости при постоянном токе в зависимости от химического состава и микроструктуры пленок аморфного гидрогенизированного углерода с наночастицами никеля $a-\mathrm{C}: \mathrm{H}(\mathrm{Ni})$ на подложках из ситалла, полученных методом реактивного ионно-плазменного магнетронного напыления.

Установлено, что пленки имеют высокие значения действительной $\left(\varepsilon^{\prime}=10-100\right)$ и мнимой $\left(\varepsilon^{\prime \prime}=30-212\right)$ частей комплексной диэлектрической проницаемости.

Определен порог протекания в пленках $a$-C:H(Ni). Концентрация $\mathrm{Ni}$, соответствующая порогу протекания, составляет 22-25 at.\%. По данным сканирующей электронной микроскопии установлено, что пленка $a-\mathrm{C}: \mathrm{H}(\mathrm{Ni})$ с концентрацией $\mathrm{Ni}$ до порога протекания представляет собой гранулированную структуру с ярко выраженными кластерными образованиями Ni размерами до $3 \mu \mathrm{m}$. При превышении концентрации никеля, соответствующей порогу протекания, в пленке наблюдается образование протяженных проводящих кластеров.

Значения удельной проводимости образцов пленок $a-\mathrm{C}: \mathrm{H}(\mathrm{Ni})$ с концентрацией никеля выше 22-25 at.\% составляют от $0.9 \cdot 10^{5}$ до $1.8 \cdot 10^{6} \mathrm{~S} / \mathrm{m}$. Металлический тип проводимости образцов подтверждается линейным ходом зависимости $R(T)$ в интервале температур от 200 до $300 \mathrm{~K}$.

Полученные результаты свидетельствуют о возможностях управления частотными зависимостями диэлектрической проницаемости и проводимостью тонких пленок $a$-C:H(Ni) путем изменения их химического состава и структуры. Установленные эффекты обусловлива- ют перспективы использования тонких пленок состава $a-\mathrm{C}: \mathrm{H}(\mathrm{Ni})$ в электронной технике.

\section{Список литературы}

[1] Robertson J. // Mater. Sci. Engineer. R: Rep. 2002. Vol. 4. N 37. P. 129-281.

[2] Koidl P., Wild C., Dischler B., Wagner J., Ramsteiner M. // Mater. Sci. Forum. 1990. Vol. 52. P. 41-70. DOI: $10.4028 /$ www.scientific.net/MSF.52-53.41

[3] Zou J.W., Reichelt K., Schmidt K., Dischler B. // J. Appl. Phys.1989. Vol. 65. N 10. P. 3914-3918. DOI: $10.1063 / 1.343355$

[4] Kaplan S., Jansen F., Machonkin M. // Appl. Phys. Lett. 1985. Vol. 47. N 7. P. $750-753$. DOI: $10.1063 / 1.96027$

[5] Grill A., Meyerson B.S., Patel V.V., Reimer A., Petrich M.A. // J. Appl. Phys. 1987. Vol. 61. N 8. P. 2874-2877. DOI: $10.1063 / 1.337883$

[6] Иванов-Омский В.И., Толмачев А.В., Ястребов С.Г. // ФТП. 2001. Т. 35. Вып. 2. С. 227-232. [Ivanov-Omskii V.I., Tolmatchev A.V., Yastrebov S.G. // Semiconductors. 2001. Vol. 35. N 2. P. 220-225. DOI: 10.1134/1.1349936]

[7] Jäger C., Gottwald J., Spiess H.W., Newport R.J. // Phys. Rev. B. 1994. Vol. 50. N 2. P. 846-852. DOI: $10.1103 /$ PhysRevB.50.846

[8] Robertson J., O’Reilly E.P. // Phys. Rev. B. 1987. Vol. 35. N 6. P. 2946-2957. DOI: 10.1103/PhysRevB.35.2946

[9] Васин А.В., Матвеева Л.А., Куцай А.М. // Письма в ЖТФ. 1999. Т. 25. Вып. 24. С. 83-87. [Vasin A.V., Matveeva L.A., Kutsai A.M. // Tech. Phys. Lett. 1999. Vol. 25. N 12. P. 1006 1007. DOI: $10.1134 / 1.1262714]$

[10] Khurshudov A., Kato K., Daisuke S. // J. Vac. Sci. Technol. A. 1996. Vol. 14. N 5. P. 2935-2939. DOI: $10.1116 / 1.580247$

[11] Wei Q., Narayan R.J., Sharma A.K., Sankar J., Narayan J. // J. Vac. Sci. Technol. A. 1999. Vol. 17. N 6. P. 3406-3414. DOI: $10.1116 / 1.582074$

[12] Dimigen H., Klages C.P. // Surf. Coat. Technol. 1991. Vol. 49. N 1-3. P. 543-547. DOI: 10.1016/0257-8972(91)90114-C

[13] He X.M., Hakovirta M., Nastasi M. // Mater. Lett. 2005. Vol. 59. N 11. P. 1417-1421. DOI: 10.1016/j.matlet.2004.11.059

[14] Damasceno J.C., Camargo S.S., Freire F.L., Carius R. // Surf. Coat. Technol. 2000. Vol. 133-134. P. 247-252. DOI: $10.1016 / \mathrm{S} 0257-8972(00) 00932-4$

[15] Gampp R., Gantenbein P., Kuster Y., Reimann P., Steiner R., Oelhafen P., Brunold S., Frei U., Gombert A., Joerger R., Graf W., Koehl M. // Opt. Mater. Technol. Energy Efficiency and Solar Energy Conversion XIII. International Society for Optics and Photonics. 1994. Vol. 2255. P. 92-107. DOI: $10.1117 / 12.185360$

[16] Donnet C., Fontaine J., Grill A., Patel V., Jahnes C., Belin M. // Surf. Coat. Technol. 1997. Vol. 94-95. P. 531536. DOI: $10.1016 / \mathrm{S} 0257-8972(97) 00462-3$

[17] Grischke M., Bewilogua K., Trojan K., Dimigen H. // Surf. Coat. Technol. 1996. Vol. 74-75. P. 739-745. DOI: $10.1016 / 0257-8972(94) 08201-4$

[18] Wei Q., Sankar J., Narayan J. // Surf. Coat. Technol. 2001. Vol. 146-147. P. 250-257. DOI: $10.1016 / \mathrm{S} 0257-8972(01) 01394-9$

[19] Луцев Л.В., Звонарева Т.К., Лебедев В.М. // Письма в ЖТФ. 2001. Т. 27. Вып. 15. С. 84-89. [Lutsev L.V., Zvonareva T.K., Lebedev V.M. // Tech. Phys. Lett. 2001. Vol. 27. N 8. P 659-661. DOI: 10.1134/1.1398960] 
[20] Луцев Л.В., Яковлев С.В., Сиклицкий В.И. // ФТТ. 2000. T. 42. Вып. 6. С. 1105-1112. [Lutsev L.V., Yakovlev S.V., Siklitskii V.I. // Phys. Sol. Stat. Vol. 42. N 6. P 1139-1146. DOI: $10.1134 / 1.1131330]$

[21] Мороз О.Ю., Наквасина Е.Ю. // Сб. трудов ХІІ Всероссийской школы-семинара „Волновые явления в неоднородных средах“. 2010. Т. 7. С. 57-60.

[22] Nikolaychuk G.A., Yakovlev S.V., Moroz O.Y., Nakvasina E.Y. // ICEEE - 2010 13th Int. Conf. on Electromechanics, Electrotechnology, Electromaterials and Components. 2010. Vol. 4. P. 46-49.

[23] Николайчук Г.А., Яковлев С.В., Луцев Л.В., Петров В.В., Мороз О.Ю., Цветкова Е.А. // 18-я Междунар. Крымская конф. „СВЧ-техника и телекоммуникационные технологии“. 2008. С. 8-12. [Nikolaychuk G.A., Yakovlev S.V., Lutsev L.V., Petrov V.V., Moroz O.Y., Tsvetkova E.A. // 18th Int. Crimean Conf. - Microwave \& Telecommunication Technology. 2008. P. 579-580. DOI: 10.1109/CRMICO.2008.4676511]

[24] Эфрос А.Л. Физика и геометрия беспорядка. М.: Наука, $1982.176 \mathrm{c}$

[25] Смирнов В.И. Неразрушающие методы контроля параметров полупроводниковых материалов и структур. Уч. пособие. Ульяновск: УлГТУ, 2012. 75 с.

[26] Baker-Jarvis J. Transmission/reflection and short-circuit line permittivity measurements. Colorado: National Institute of Standards and Technology, 1990. $151 \mathrm{p}$.

[27] Nicholson A.M., Ross G.F. // IEEE Trans. Instrum. Meas. 1970. Vol. 4. N 4. P. 377-182. DOI: $10.1109 /$ TIM.1970.4313932

[28] Weir W.B. // Proc. IEEE. 1974. Vol. 62. N 1. P. 33-36. DOI: 10.1109/PROC.1974.9382

[29] Bartley P.G., Begley S.B. // Instrumentation and Measurement Technology Conference (I2MTC). 2010. P. 54-57. DOI: 10.1109/IMTC.2010.5488184

[30] Ковалев И.С. Конструирование и расчет полосковых устройств. М.: Сов. радио, 1974. 295 с.

[31] Jonscher A.K. // J. Phys. D: Appl. Phys. 1999. Vol. 32. N 14. P. R57. DOI: $10.1088 / 0022-3727 / 32 / 14 / 201$

[32] Иванов-Омский В.И., Фролова Г.С. // ЖТФ. 1995. Т. 65. Вып. 9. C. 186-189. [Ivanov-Omskii V.I., Frolova G.S. // J. Tech. Phys. 1995. Vol. 40. N 9. P. 966-967].

[33] Hallouet B., Wetzel B., Pelster R. // J. Nanomaterials. 2007. Vol. 2007. P. 34527. DOI: $10.1155 / 2007 / 34527$

[34] Pelster R., Simon U. // Colloid Polym Sci. 1999. Vol. 227. N 1. P. 2-14. DOI: $10.1007 / \mathrm{s} 003960050$

[35] Anton R. // Carbon. 2008. Vol. 46. N 4. P. 656-662. DOI: 10.1016/j.carbon.2008.01.021

[36] Du Y., Xu M., Wu J., Shi Y., Lu H. // J. Appl. Phys. 1991. Vol. 70. N 10. P. 5903-5905. DOI: 10.1063/1.3501 